\title{
Erratum to: Global and regional ocean carbon uptake and climate change: sensitivity to a substantial mitigation scenario
}

\author{
Marcello Vichi · Elisa Manzini • Pier Giuseppe Fogli • \\ Andrea Alessandri · Lavinia Patara $\cdot$ Enrico Scoccimarro • \\ Simona Masina $\cdot$ Antonio Navarra
}

Published online: 24 July 2011

(C) Springer-Verlag 2011

\section{Erratum to: Clim Dyn \\ DOI 10.1007/s00382-011-1079-0}

In the original publication of this article, Fig. 8 was published without the vertical bars indicated in the caption. The correct figure is produced here.

The online version of the original article can be found under doi:10.1007/s00382-011-1079-0.

M. Vichi (凹) · E. Manzini · P. G. Fogli · A. Alessandri ·

L. Patara $\cdot$ S. Masina $\cdot$ A. Navarra

Centro Euro-Mediterraneo per i Cambiamenti Climatici

(CMCC), Viale Aldo Moro 44, 40127 Bologna, Italy

e-mail: marcello.vichi@cmcc.it

M. Vichi - E. Manzini - E. Scoccimarro - S. Masina .

A. Navarra

Istituto Nazionale di Geofisica e Vulcanologia,

Bologna, Italy

Present Address:

E. Manzini

Max Planck Institute for Meteorology, Hamburg, Germany

L. Patara

Leibniz Institute of Marine Sciences (IFM-GEOMAR),

Kiel, Germany

Present Address:

A. Alessandri

ENEA, Rome, Italy

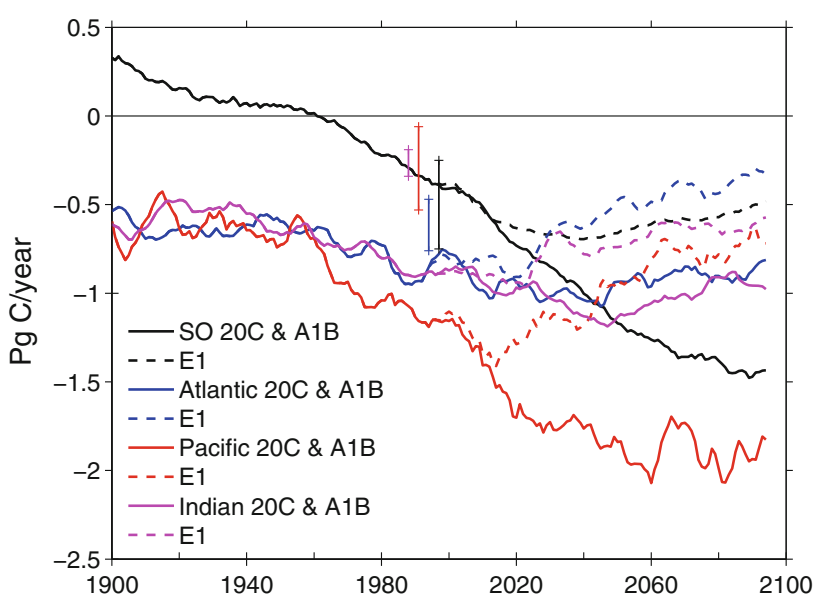

Fig. 8 Ocean carbon uptake in the 20C, A1B and E1 simulations divided into major basin contributions (11 years running means, negative values mean ocean uptake). The Southern Ocean $(S O)$ is defined as the area southern of $50^{\circ} \mathrm{S}$. The range of estimates for contemporary net $\mathrm{CO}_{2}$ fluxes from Gruber et al. (2009) are shown as vertical bars with the relative colour for each basin 